\title{
Exploring the application of the Prototype Willingness Model to weight loss dieting behaviour among UK adults
}

\section{TITLE PAGE}

Authors: Rachel Instone \& Emma L. Davies

Department of Psychology, Faculty of Health and Life Sciences, Oxford Brookes University, Headington Campus, Gipsy Lane, Oxford, OX3 0BP, United Kingdom

Corresponding author: Emma L Davies edavies@brookes.ac.uk

orcid.org/0000-0003-3577-3276

Running head: Prototype Willingness Model and weight loss dieting behaviour

\section{Word count: 2975}

RI and ED designed the study. RI collected the data, conducted literature searches and provided summaries of previous research studies. Both authors contributed to the analysis. RI wrote the first draft of the manuscript and both authors contributed to and have approved the final manuscript.

Acknowledgements: The authors would like to thank the participants for taking the time to complete the measures. 


\title{
Exploring the application of the Prototype Willingness Model to weight loss dieting behaviour among UK adults
}

\begin{abstract}
Frequent weight loss dieting leads to increased BMI and is associated with eating pathologies. Theoretical models can aid the development of interventions to reduce risk behaviours such as frequent dieting if they are able to adequately account for the target behaviour. The Prototype Willingness Model (PWM) may be able to account for weight loss dieting as this behaviour is often associated with social images. This study explored whether the PWM could predict weight loss dieting status over and above the Theory of Planned Behaviour (TPB). One hundred and ninety two participants (69\% female; mode age 35-44) completed PWM and TPB measures and recorded their height and weight. Males were more likely to be non-dieters than females. Frequent dieters had a higher BMI than non-dieters and rated themselves as more similar to the overweight prototype. Prototype perceptions predicted willingness to eat unhealthy foods alone. Similarity to the overweight prototype predicted weight loss dieting status over and above TPB measures and sex. Further research should explore prototype perceptions in an obese/overweight frequent dieting population as this may be a fruitful direction for developing interventions to reduce weight loss dieting.
\end{abstract}




\section{Exploring the application of the Prototype Willingness Model to weight loss dieting behaviour among UK adults}

\section{INTRODUCTION}

Obesity is associated with heart disease, diabetes, and cancer, and people who are perceived to be overweight often face stigma (WHO, 2017). At any point in time, it has been estimated that about $40 \%$ of the global population may be attempting to restrict calorie intake in order to reduce their weight (Santos, Sniehotta, Marques, Carraça, \& Teixeira, 2016). In the United Kingdom (UK), for example, around 50\% of the population attempted to lose weight in 2015 , however many of those people were unsuccessful in their goal (Mintel, 2016). Problematically, evidence suggests that weight loss dieting (WLD) actually leads to increased BMI (NeumarkSztainer, Wall, Story, \& Standish, 2012; Siahpush et al., 2015). WLD is also associated with eating pathologies (Lowe \& Timko, 2004; Neumark-Sztainer et al., 2006). Thus, interventions to reduce engagement in WLD are required. Health psychologists have highlighted the importance of using theory for successful intervention development (Albarracin et al., 2005). It is crucial, therefore, to understand the theoretical drivers of WLD.

The Theory of Planned Behaviour (TPB), (Ajzen, 1991) is widely used for investigating health behaviours. In the TPB, behaviours are determined by intentions, which are a product of attitudes, subjective norms, and perceived behavioural control (PBC). A systematic review of TPB interventions found only small to moderate effect sizes (Hardeman et al., 2002), but despite this, the TPB remains a popular basis for interventions (Sniehotta, Presseau, \& Araujo-Soares, 2014). The TPB may be particularly lacking when it comes to WLD as this behaviour is often influenced by media images of body shapes (Fernandez \& Pritchard, 2012). Dieting is also associated with personal body image concerns, where the thin ideal is internalized (Thompson \& Stice, 2001), and may in part be motivated by a fear of fatness because of such societal ideals (Dalley, Toffanin, \& Pollet, 2012). Perceived weight status may paradoxically lead to increased 
weight (Robinson, Hunger, \& Daly, 2015) because more weight loss attempts are made, this is further associated with weight gain (Haynes, Kersbergen, Sutin, Daly, \& Robinson, 2017). Thus, perception of oneself is an important determinant of WLD and warrants further attention.

One theory that takes such perceptions into account is the Prototype Willingness Model (PWM) (Gerrard, Gibbons, Houlihan, Stock, \& Pomery, 2008; Gibbons \& Gerrard, 1995). Within this model, there are two routes to behaviour. The first is a planned route, via attitudes, social norms and intentions, similar to the ТРВ. The second is via 'prototypes' and 'willingness' and is postulated to operate in a more spontaneous manner to the planned route. Two elements of prototype perception are important- 'favourability' (how appealing the prototype is to the individual) and 'similarity' (how similar the individual perceives themselves to be to the prototype). The PWM is thought to have particular success at predicting risk behaviours in this adolescents because they are, in general, very image conscious and therefore sensitive to peers' approval or disapproval (Gerrard et al., 2008). However, the developmental trajectory of this sensitivity is unknown and it may be that older adults are still susceptible to image-conscious tendencies that may influence their behaviours (Gibbons \& Gerrard, 2016).

Gerrits et al (Gerrits, de Ridder, de Wit, \& Kuijer, 2009; Gerrits et al., 2010) explored healthy and unhealthy eating in adolescents. Adolescents had favourable perceptions of healthy eaters but these were unrelated to eating behaviours. Unhealthy eater prototypes on the other hand, were related to diet and eating, suggesting this could be a meaningful intervention target in this age group (Gerrits et al., 2009; Gerrits et al., 2010). In an female adult population, the influence of fat and thin prototypes on WLD behaviour was unequal (Dalley \& Buunk, 2009). As perceived similarity to the fat prototype increased and favourability decreased, WLD increased. Thin prototype favourability did not predict WLD. This finding converges with previous research that suggests the proximity to the undesired self rather than distance from the desired self, influences behaviour. The study did not use a wide weight range with most participants in the normal BMI range (mean=22.16, $\mathrm{SD}=3.00$ ) and findings may differ for an overweight or obese 
cohort. The present study builds on Dalley and Buunk's (2009) study in two main ways. Firstly, it tests how well the whole PWM can predict WLD behaviours over and above the TPB in a sample of adults over the age of 25. Second, it explores two aspects of 'willingness': willingness to eat unhealthily socially and alone.

Eating is often a social activity and there is good evidence to show how important social contexts, and other people are to eating habits (Higgs \& Thomas, 2016), supporting the application of a model that takes into account social factors. In the PWM willingness is usually measured by the creation of risk conducive social situations. However, it may be that prototype perceptions also influence eating habits outside of these contexts. Thus, it is of interest to explore whether prototype perceptions also influence willingness to eat alone.

As far as the authors can ascertain, the current study is the first application of both the TPB and the PWM to an older (25+) adult population in relation to WLD. The PWM was designed for adolescents, however, a meta-analysis found that adult research provided similar results (Todd, Kothe, Mullan, \& Monds, 2016).

\section{Aims and hypotheses}

The purpose of this paper was to explore the application of the PWM and TPB to WLD in an adult population. The specific aims were to 1) to explore willingness to eat unhealthy foods socially or when alone and (2) if the PWM would predict WLD status over and above the TPB. We hypothesized that prototype perceptions would explain more of the variance in willingness to eat socially than willingness to eat alone, given the assumed social nature of prototypes. We also hypothesized that the PWM would be able to explain a greater proportion in WLD behaviour than the TPB.

\section{METHODS}

\section{Participants and procedure}


Adults resident in the UK aged 25 and over were recruited through social media with invitations to participate posted in weight loss/dieting Facebook groups and Twitter. In total 192 people took part (56\% completion rate; $69 \%$ female; $93 \%$ white; median age $45-54 ; 75 \%$ educated to degree level or higher; 77\% employed; 66\% living with a partner). A cross-sectional anonymous survey was delivered using Qualtrics and measures were counterbalanced. The survey took approximately 15 minutes to complete and was approved by Oxford Brookes Psychology Ethics Committee.

\section{Measures}

All survey measures can be seen in Appendix A.

\section{Theory of Planned Behaviour}

Following guidance on writing a TPB questionnaire (Francis et al., 2004) the following constructs were measured using seven point scales; behavioural intentions; attitudes; subjective norms; and PBC. Each construct was measured with a number of items which were summed to produce a single scale and tested for internal reliability: Intentions ( 6 items; $\alpha=$ .64 ); attitudes ( 8 items; $\alpha=.76$ ); norms (7 items; $\alpha=.72$ ); perceived behavioural control (3 items; $\alpha=.51)$.

\section{Prototype Willingness Model}

Perceptions of slim and overweight prototypes were measured in line with previous research (Gibbons, Gerrard, \& McCoy, 1995). Favourability was measured using 12 pairs of antonyms from previous studies (Blanton et al., 2001; Dalley \& Buunk, 2009) (e.g. Irresponsible/Responsible) which were rated on a seven point scale and summed (slim prototype, 12 items; $\alpha=.83$, overweight prototype; 12 items; $\alpha=.81$ ). Similarity was measured by asking participant to rate themselves on a seven point scale from 'Not at all similar/Very similar' to each prototype. Willingness to each unhealthy food socially or alone was measured 
on a seven point scale (1-7, 'Not willing/Very willing') using scenarios related to eating unhealthy food socially ( 8 items; $\alpha=.66$ ) or alone ( 3 items; $\alpha=.81$ ).

\section{Dieting and weight}

In line with previous research (Canpolat, Orsel, Akdemir, \& Ozbay, 2005; Dalley \& Buunk, 2009) WLD status was measured with the Dieting Status Measure (DSM) (Strong \& Huon, 1997). Participants ticked one of the six categories ranging from 'Never dieted' to Frequent dieter' that they perceived best fitted their dieting behaviour, for example a 'Trier' (I have given it a go but never really got very far'). Body mass index (BMI) was calculated using self-reported height and weight, this varies by 1-3\% from actual height and weight (Bowman \& DeLucia, 1992). Healthy food was defined in the survey based on NHS guidelines of five portions of fruit and vegetables each day and choosing high fibre or wholegrain options and limiting sugar and high fat foods. Unhealthy food was described as being high in sugar and fats and examples were given such as chips and cakes.

\section{RESULTS}

Missing data were dealt with using pairwise deletion. The dieting status scale was collapsed into three groups. "Triers" and "Ex-dieters" were included in the "Sometimes Dieters" group and "Often" and "Always" dieters formed the "Frequent Dieters" group. The number of participants who had never dieted (ND) was 46; 107 participants fell into the sometimes dieters category (SD) and 34 participants into the frequent dieters category (FD). There was a significant association between sex and dieting status $(\chi 2(2)=13.81, p=.001)$, with a greater proportion of males in the ND group $(40.4 \%$ of the males were in the ND group compared to $17.1 \%$ of females), and a greater proportion of the females in the FD group ( $23.3 \%$ of females, compared to $10.7 \%$ of males; the SD group was more equal with $59.7 \%$ of females and $50.9 \%$ of males in this category). However there were no significant differences between females and males on the main study measures after adjustments were made for multiple comparisons, other than for 
favorability of and similarity to overweight prototype. Females $(M=47.78, S D=8.15)$ rated the overweight prototype significantly more favourably than males $(\mathrm{M}=43.13, \mathrm{SD}=7.62 ; \mathrm{t}(183)$ $=3.62, \mathrm{p}<.001)$. Females $(\mathrm{M}=4.12, \mathrm{SD}=1.84)$ rated themselves as significantly more similar to the overweight prototype than males $(\mathrm{M}=3.12, \mathrm{SD}=1.45 ; \mathrm{t}(132.96)=4.00, \mathrm{p}<001$.

Means and standard deviations for the study measures for the whole sample are shown in Table 1. The BMI range was $16.64-70.29(\mathrm{M}=25.51, \mathrm{SD}=8.09)$ : there were 4 participants in the underweight category, 92 in the normal weight category, 54 in the overweight category, and 31 in the obese category. Significant positive correlations were found between the overweight prototype favourability and similarity, overweight similarity and willingness to eat unhealthily alone and between slim prototype similarity and $\mathrm{PBC}(\mathrm{p}<.01)$. Significant negative correlations were found between overweight prototype similarity and willingness to eat unhealthily socially, and between slim prototype similarity and willingness to eat unhealthily alone and between overweight prototype similarity and $\mathrm{PBC}(\mathrm{p}<.01)$.

\section{[Insert Table 1]}

Each group was then compared on the main study measures (Table 2). There was a significant difference in BMI across the three dieting statuses $(F(2,185)=4.57 \mathrm{p}=.012$ partial $\eta 2=.047)$. Post-hoc tests revealed that there was no significant different between the SD and the FD, but the ND had a significantly lower BMI than the other two groups. The groups were different in how they rated the similarity of both prototypes. ND were significantly more similar to the slim prototype $(F(2,186)=6.95 p=.001$ partial $\eta 2=.069)$ than the other two groups. SD and FD were significantly more similar to the overweight prototype $(\mathrm{F}(2,186)=10.16 \mathrm{p}=.001$ partial $\eta 2=.098$ ). The other differences were rendered non-significant once multiple comparisons were accounted for.

There was no significant difference in willingness to eat unhealthy foods socially between the dieting groups (Table 2). However, there was a significant difference in willingness to eat 
unhealthy foods alone $(F(2,185)=4.22 p=.016$ partial $\eta 2=.044)$. Post-hoc tests revealed that there was no significant difference in willingness to eat unhealthy food alone between the FD and the ND. However, there was a significant difference in willingness to eat alone between the ND and the SD with the SD more willing to eat unhealthy foods when alone than the ND.

However as above we must take account of the number of multiple comparisons when considering this finding.

\section{[Insert Table 2]}

Because willingness is conceptualized in the PWM as a social reaction variable, multiple linear regression was performed to determine if prototype favourability and similarity would predict willingness to eat unhealthy food socially and willingness to eat unhealthy food alone (Table 2). While only similarity to the overweight prototype predicted willingness to eat unhealthy foods socially, willingness to eat unhealthy foods alone was predicted by overweight prototype favourability and similarity, as well as slim prototype similarity.

\section{[Insert Table 3]}

A multinomial logistic regression was conducted with dieting status as the outcome measure and frequent dieter as the reference category (Table 2). Firstly, TPB measures were used as predictors of dieting status. The resulting model was significant and correctly classified $59.8 \%$ of cases $R^{2}=.152$ (Cox \& Snell) .177 (Nagelkerke), $\chi^{2}(10)=29.51, p=.001$. Compared to frequent dieters, non-dieters had higher $\mathrm{PBC}(\mathrm{OR}=1.20)$ and were more likely to be male $(\mathrm{OR}=.13)$. There were no differences between frequent dieters and sometimes dieters in this model, although intentions approached significance $(\mathrm{p}=.053)$.

[Insert table 4] 
In the following regression (Table 3), PWM variables were added to the model. This model was significant and classified $64.7 \%$ of cases $\left(\mathrm{R}^{2}=.301\right.$ (Cox \& Snell) .351 (Nagelkerke), $\chi^{2}(22)=$ 60.89, $\mathrm{p}<.001)$. In this model, the TPB variable PBC was rendered non-significant.

[Insert table 5]

Compared to frequent dieters, non-dieters had higher levels of similarity to the slim prototype $(\mathrm{OR}=2.10)$ and lower levels of similarity to the overweight prototype $(\mathrm{OR}=0.62)$. Compared to frequent dieters, sometimes dieters had lower and lower levels of intentions (OR $=0.92)$. Sex did not contribute to this model.

\section{DISCUSSION}

The purpose of this paper was to explore the application of the PWM and TPB to WLD behaviours. The specific aims were to 1 ) to explore willingness to eat unhealthy foods socially or when alone and (2) if the PWM would predict WLD status over and above the TPB.

Frequent dieters had higher BMIs than non-dieters, supporting the need to explore ways of discouraging this behaviour. The findings also suggest that 'sometimes dieters' may be more willing to eat unhealthy foods alone compared to 'non-dieters'. Some evidence points towards differences including 'emotional eating', 'food fretting' (worrying about what is eaten and guilt associations) and 'social fare' (eating less when in company than when alone) (Scherwitz \& Kesten, 2005). These different eating styles could be incorporated into future exploration of the PWM. In the current study, only overweight prototype similarity predicted willingness to eat unhealthy food socially, but both favourability and similarity to the overweight prototype predicted willingness to eat alone.

As expected, males were more likely to be non-dieters than females. However, theory based measures were able to add to the prediction of dieting status when sex was controlled for. Nondieters had higher levels of PBC and were more likely to be male than frequent dieters. Studies 
that have used the TBP as a basis for interventions have not always yielded positive results, leading some to suggest that the TPB be 'retired' (Sniehotta et al., 2014). In the current study, the addition of the PWM measures increased the amount of variance explained and classified a higher percentage of the cases. PBC was also rendered non-significant as a predictor of dieting status. In line with previous findings (Dalley \& Buunk, 2009) similarity to the overweight prototype predicted WLD status, indicating that it may be identifying with an undesired self that motivates WLD. Thus, an individual identifying as similar to the overweight prototype may behave in a way that will fulfill that self-image, which may explain the paradox of frequent dieting (van Lettow, de Vries, Burdorf, \& van Empelen, 2014).

Targeting similarity to prototypes could be used to reduce WLD behaviours. This is important to change because even perceiving oneself as overweight is associated with future weight gain (Robinson et al., 2015). However, at present there are no uniform methods of targeting prototypes within interventions (Davies, Martin, \& Foxcroft, 2016). It is also important to avoid stigmatizing people who are overweight or obese (Hunger, Major, Blodorn, \& Miller, 2015), thus further research is needed to determine how the overweight prototype should be targeted in order to have a positive impact on reducing frequent dieting behaviour. If 'fear of fat' is the primary motivator for frequent WLD (Dalley \& Buunk, 2009) future experimental studies could investigate whether improving the favourability of the overweight prototype decreases the frequency of WLD. It may be possible to alter prototype similarity by indirect means. For example, this could be achieved by assisting individuals to reject societal ideas of thinness espoused by the media. A systematic review found that media literacy interventions were able to reduce shape and weight concerns in females and males (Le, Barendregt, Hay, \& Mihalopoulos, 2017)

Limitations to this study should be considered. As this is a cross sectional study, we cannot infer causality, and future research using a prospective design could be conducted. It may be beneficial to undertake further qualitative research to ascertain whether the characteristics 
used to measure prototype favourability are relevant. There was an uneven spread of participants in the three dieting status, as well as an unequal number of males and females, and a larger sample size gained by better targeting of the different groups may have helped address this. Further, as much research has previously highlighted, BMI can be a problematic means of determining poor health (Tomiyama, Hunger, Nguyen-Cuu, \& Wells, 2016). Prototype favourability did not significantly predict dieting status. This could be due to the use of selfreport questionnaires which allow time for reflection and adjustments to initial reactions in line social desirability bias. Future studies could explore the model using implicit measures, as these may be more suitable for capturing heuristic reactions in risky health behaviours (Davies, Paltoglou, \& Foxcroft, 2017).

In conclusion, prototype similarity predicted dieting status. Further prospective studies are needed to explore prototype perceptions in greater depth within in an obese/overweight frequent dieting population, as moderating similarity to the overweight prototype may be a fruitful direction for developing interventions. 


\section{REFERENCES}

Ajzen, I. (1991). The theory of planned behavior. Organizational Behavior and Human Decision Processes, 50(2), 179-211.

Albarracin, D., Gillette, J. C., Earl, A. N., Glasman, L. R., Durantini, M. R., \& Ho, M. H. (2005). A test of major assumptions about behavior change: A comprehensive look at the effects of passive and active HIV-prevention interventions since the beginning of the epidemic. Psychological Bulletin, 131(6), 856-897. doi:10.1037/0033-2909.131.6.856

Blanton, H., VandenEijnden, R., Buunk, B. P., Gibbons, F. X., Gerrard, M., \& Bakker, A. (2001). Accentuate the negative: Social images in the prediction and promotion of condom use. Journal of Applied Social Psychology, 31(2), 274-295.

Bowman, R. L., \& DeLucia, J. L. (1992). Accuracy of self-reported weight: A meta-analysis. Behavior Therapy, 23(4), 637-655. doi:10.1016/S0005-7894(05)80226-6

Canpolat, B. I., Orsel, S., Akdemir, A., \& Ozbay, M. H. (2005). The relationship between dieting and body image, body ideal, self-perception, and body mass index in Turkish adolescents. International Journal of Eating Disorders, 37(2), 150-155. doi:10.1002/eat.20081

Dalley, S. E., \& Buunk, A. P. (2009). "Thinspiration" vs. "fear of fat". Using prototypes to predict frequent weight-loss dieting in females. Appetite, 52(1), 217-221. doi:10.1016/j.appet.2008.09.019

Dalley, S. E., Toffanin, P., \& Pollet, T. V. (2012). Dietary restraint in college women: Fear of an imperfect fat self is stronger than hope of a perfect thin self. Body Image, 9(4), 441-447. doi:10.1016/j.bodyim.2012.06.005

Davies, E. L., Martin, J., \& Foxcroft, D. R. (2016). Development of an adolescent alcohol misuse intervention based on the Prototype Willingness Model: A Delphi study. Health Education, 116(3).

Davies, E. L., Paltoglou, A. E., \& Foxcroft, D. R. (2017). Implicit alcohol attitudes predict drinking behaviour over and above intentions and willingness in young adults but willingness is more important in adolescents: Implications for the Prototype Willingness Model. British Journal of Health Psychology, 22(2), 238-253. doi:10.1111/bjhp.12225

Fernandez, S., \& Pritchard, M. (2012). Relationships between self-esteem, media influence and drive for thinness. Eating Behaviors, 13(4), 321-325. doi:https://doi.org/10.1016/i.eatbeh.2012.05.004

Francis, J., Eccles, M., Johnston, M., Walker, A., Grimshaw, J., Foy, R., . . Bonetti, D. (2004). Theory of Planned Behaviour Questionnaires: Manual for Researchers. In. Newcastle: Centre for Health Services Research, University of Newcastle.

Gerrard, M., Gibbons, F. X., Houlihan, A. E., Stock, M. L., \& Pomery, E. A. (2008). A dual-process approach to health risk decision making: The prototype willingness model. Developmental Review, 28(1), 29-61. doi:10.1016/j.dr.2007.10.001

Gerrits, J. H., de Ridder, D. T. D., de Wit, J. B. F., \& Kuijer, R. G. (2009). Cool and independent or foolish and undisciplined? Adolescents' prototypes of (un)healthy eaters and their association with eating behaviour. Appetite, 53(3), 407-413. doi:10.1016/j.appet.2009.08.008

Gerrits, J. H., O'Hara, R. E., Piko, B. F., Gibbons, F. X., de Ridder, D. T. D., Keresztes, N., . . de Wit, J. B. F. (2010). Self-control, diet concerns and eater prototypes influence fatty foods consumption of adolescents in three countries. Health Education Research, 25(6), 10311041. doi:10.1093/her/cyq055

Gibbons, F. X., \& Gerrard, M. (1995). Predicting Young-Adults Health Risk Behavior. Journal of Personality and Social Psychology, 69(3), 505-517. doi:http://dx.doi.org/10.1037/0022$\underline{3514.69 .3 .505}$ 
Gibbons, F. X., \& Gerrard, M. (2016). Reactions to the meta-analyses of the Prototype Willingness Model. Health Psychology Review, 10(1), 44-46.

doi:10.1080/17437199.2015.1116020

Gibbons, F. X., Gerrard, M., \& McCoy, S. B. (1995). Prototype perception predicts (lack of) pregnacy prevention. Personality and Social Psychology Bulletin, 21(1), 85-93. doi:doi: 10.1177/0146167295211009

Hardeman, W., Johnston, M., Johnston, D. W., Bonetti, D., Wareham, N. J., \& Kinmonth, A. L. (2002). Application of the theory of planned behaviour in behaviour change interventions: A systematic review. Psychology \& Health, 17(2), 123-158. doi:10.1080/08870440290013644

Haynes, A., Kersbergen, I., Sutin, A., Daly, M., \& Robinson, E. (2017). A systematic review of the relationship between weight status perceptions and weight loss attempts, strategies, behaviours and outcomes. Obesity Reviews, 19(3), 347-363. doi:10.1111/obr.12634

Higgs, S., \& Thomas, J. (2016). Social influences on eating. Current Opinion in Behavioral Sciences, 9, 1-6. doi:https://doi.org/10.1016/i.cobeha.2015.10.005

Hunger, J. M., Major, B., Blodorn, A., \& Miller, C. T. (2015). Weighed Down by Stigma: How Weight-Based Social Identity Threat Contributes to Weight Gain and Poor Health. Social and Personality Psychology Compass, 9(6), 255-268. doi:10.1111/spc3.12172

Le, L. K.-D., Barendregt, J. J., Hay, P., \& Mihalopoulos, C. (2017). Prevention of eating disorders: A systematic review and meta-analysis. Clinical Psychology Review, 53, 46-58. doi:https://doi.org/10.1016/j.cpr.2017.02.001

Lowe, M. R., \& Timko, C. A. (2004). Dieting: really harmful, merely ineffective or actually helpful? Br J Nutr, 92 Suppl 1, S19-22.

Mintel. (2016). Attitudes Towards Healthy Eating UK 2016. Retrieved from London:

Neumark-Sztainer, D., Wall, M., Guo, J., Story, M., Haines, J., \& Eisenberg, M. (2006). Obesity, Disordered Eating, and Eating Disorders in a Longitudinal Study of Adolescents: How Do Dieters Fare 5 Years Later? Journal of the Academy of Nutrition and Dietetics, 106(4), 559-568. doi:10.1016/j.jada.2006.01.003

Neumark-Sztainer, D., Wall, M., Story, M., \& Standish, A. R. (2012). Dieting and unhealthy weight control behaviors during adolescence: Associations with 10-year changes in body mass index. The Journal of adolescent health : official publication of the Society for Adolescent Medicine, 50(1), 80-86. doi:10.1016/j.jadohealth.2011.05.010

Robinson, E., Hunger, J. M., \& Daly, M. (2015). Perceived weight status and risk of weight gain across life in US and UK adults. International Journal Of Obesity, 39, 1721. doi:10.1038/ijo.2015.143

https://www.nature.com/articles/ijo2015143\#supplementary-information

Santos, I., Sniehotta, F. F., Marques, M. M., Carraça, E. V., \& Teixeira, P. J. (2016). Prevalence of personal weight control attempts in adults: a systematic review and meta - analysis. Obesity Reviews, 18(1), 32-50. doi:10.1111/obr.12466

Scherwitz, L., \& Kesten, D. (2005). Seven eating styles linked to overeating, overweight, and obesity. Explore (NY), 1(5), 342-359. doi:10.1016/j.explore.2005.06.004

Siahpush, M., Tibbits, M., Shaikh, R. A., Singh, G. K., Sikora Kessler, A., \& Huang, T. T. K. (2015). Dieting Increases the Likelihood of Subsequent Obesity and BMI Gain: Results from a Prospective Study of an Australian National Sample. International Journal of Behavioral Medicine, 22(5), 662-671. doi:10.1007/s12529-015-9463-5

Sniehotta, F. F., Presseau, J., \& Araujo-Soares, V. (2014). Time to retire the theory of planned behaviour. Health Psychology Review, 8(1), 1-7. doi:10.1080/17437199.2013.869710

Stock, M. L., Gerrard, M., Gibbons, F. X., Dykstra, J. L., Mahler, H. I. M., Walsh, L. A., \& Kulik, J. A. (2009). Sun Protection Intervention for Highway Workers: Long-Term Efficacy of UV Photography and Skin Cancer Information on Men's Protective Cognitions and Behavior. Annals of Behavioral Medicine, 38(3), 225-236. doi:10.1007/s12160-009-9151-2 
Strong, K. G., \& Huon, G. F. (1997). The development and evaluation of a stage-based dieting status measure (DiSM). Eating Disorders, 5(2), 97-104. doi:10.1080/10640269708249212

Thompson, J. K., \& Stice, E. (2001). Thin-ideal internalization: Mounting evidence for a new risk factor for body-image disturbance and eating pathology. Current Directions in Psychological Science, 10(5), 181-183. doi:10.1111/1467-8721.00144

Todd, J., Kothe, E., Mullan, B., \& Monds, L. (2016). Reasoned versus reactive prediction of behaviour: a meta-analysis of the prototype willingness model. Health Psychology Review, 10(1), 1-24. doi:10.1080/17437199.2014.922895

Tomiyama, A. J., Hunger, J. M., Nguyen-Cuu, J., \& Wells, C. (2016). Misclassification of cardiometabolic health when using body mass index categories in NHANES 2005-2012. Int J Obes (Lond), 40(5), 883-886. doi:10.1038/ijo.2016.17

van Lettow, B., de Vries, H., Burdorf, A., \& van Empelen, P. (2014). Quantifying the strength of the associations of prototype perceptions with behaviour, behavioural willingness and intentions: a meta-analysis. Health Psychology Review, 1-19. doi:10.1080/17437199.2014.941997

WHO. (2017). Obesity and overweight. In. Geneva: World Health Organization. 
TABLES \& FIGURES

Table 1: Pearson correlations between theory of planned behaviour and prototype willingness model constructs and BMI

\begin{tabular}{|c|c|c|c|c|c|c|c|c|c|c|c|c|c|}
\hline & \multicolumn{2}{|c|}{ Slim Prototype } & \multicolumn{2}{|c|}{$\begin{array}{l}\text { Overweight } \\
\text { Prototype }\end{array}$} & \multicolumn{2}{|c|}{ Willingness to eat unhealthily } & Attitudes & Norms & PBC & Intentions & BMI & Mean & SD \\
\hline & (a)Fav & (b) Sim & (c)Fav & (d)Sim & (e)socially & (f)alone & (g) & (h) & (i) & (j) & $(\mathrm{k})$ & & \\
\hline (a) & - & & & & & & & & & & & 53.72 & 7.46 \\
\hline (b) & $.15^{*}$ & - & & & & & & & & & & 4.18 & 1.47 \\
\hline (c) & -.03 & -.09 & - & & & & & & & & & 46.39 & 8.27 \\
\hline (d) & $-.15^{*}$ & $-.21^{* *}$ & $.28^{* *}$ & - & & & & & & & & 3.84 & 1.78 \\
\hline (e) & -.02 & .10 & .01 & $-.27^{* *}$ & - & & & & & & & 30.31 & 8.00 \\
\hline (f) & -.06 & $-.23^{* *}$ & -.04 & $.42^{* *}$ & $-.46^{* *}$ & - & & & & & & 11.30 & 4.79 \\
\hline (g) & $.20^{* *}$ & $.31^{* *}$ & .03 & $-.26^{* *}$ & $.33^{* *}$ & $-.28^{* *}$ & - & & & & & 44.76 & 6.87 \\
\hline (h) & $.18^{*}$ & -.02 & -.04 & .02 & $.15^{*}$ & -.06 & $.23^{* *}$ & - & & & & 30.64 & 7.16 \\
\hline (i) & .06 & $.37^{* *}$ & .08 & $-.32^{* *}$ & $.34^{* *}$ & $-.43^{* *}$ & $.49^{* *}$ & $.17^{*}$ & - & & & 15.87 & 3.39 \\
\hline (j) & $.17^{*}$ & $.18^{*}$ & -.02 & $-.15^{*}$ & $.43^{* *}$ & $-.37 * *$ & $.36^{* *}$ & $.35^{* *}$ & $.35^{* *}$ & - & & 28.32 & 6.51 \\
\hline (k) & .01 & $-.37^{* *}$ & .04 & $.29^{* *}$ & $-.18^{*}$ & $20^{* *}$ & $-.24^{* *}$ & .07 & $-.35^{* *}$ & .02 & - & 25.51 & 8.03 \\
\hline
\end{tabular}

${ }^{* *} p<0.01$ level (2-tailed), ${ }^{*} p<0.05$ level (2-tailed) 
Table 2: Mean and standard deviation for all study measures by dieter group

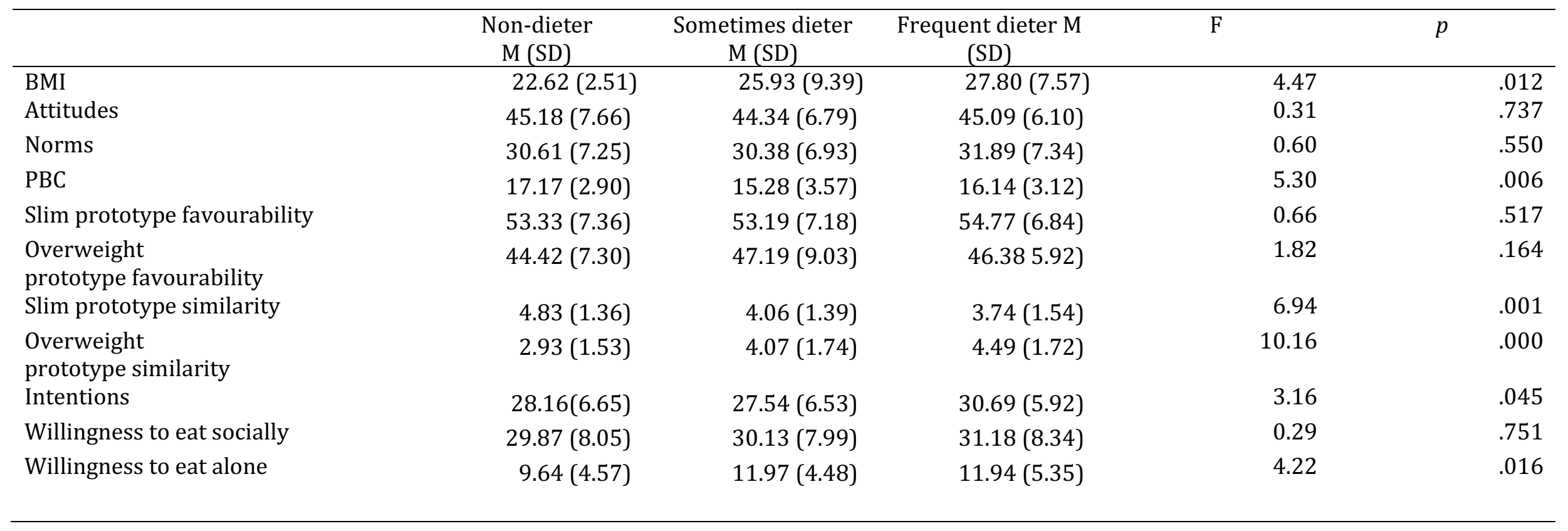


Table 3: Results of multiple linear regression analyses predicting willingness to eat unhealthy food socially and alone from prototype perceptions

\begin{tabular}{lcccc}
\hline & Socially & \multicolumn{2}{c}{ Alone } & \\
& $\beta$ & $p$ & $\beta$ & $p$ \\
\hline Constant & & .000 & & .000 \\
Overweight prototype & .099 & .189 & -.200 & .004 \\
favourability & & & & .918 \\
Slim prototype favourability & -.057 & .436 & .007 & .000 \\
Overweight prototype similarity & -.330 & .000 & .484 & .045 \\
Slim prototype similarity & .036 & .624 & -.136 & \\
\hline
\end{tabular}

Notes: Willingness to eat unhealthy food socially: $R^{2}=.102, \mathrm{~F}=5.03, \mathrm{p}=.001$

Willingness to eat unhealthy food alone: $R^{2}=.255, \mathrm{~F}=15.35, \mathrm{p}<.001$. 
Table 4: Multinomial logistic regression with TPB constructs and sex predicting dieting status.

\begin{tabular}{|c|c|c|c|c|c|c|}
\hline & \multirow[b]{2}{*}{$\boldsymbol{B}$} & \multirow[b]{2}{*}{ SE } & \multicolumn{4}{|c|}{ 95\% CI for Odds Ratio } \\
\hline & & & $p$ & Lower & $\begin{array}{l}\text { Odds } \\
\text { Ratio }\end{array}$ & Upper \\
\hline \multicolumn{7}{|l|}{$\begin{array}{l}\text { Non dieter vs. Frequent } \\
\text { dieter }\end{array}$} \\
\hline Intercept & .765 & 1.937 & .693 & & & \\
\hline Attitudes & .006 & .043 & .892 & .925 & 1.006 & 1.094 \\
\hline Norms & -.012 & .037 & .737 & .920 & .988 & 1.061 \\
\hline Perceived Behavioural Control & .183 & .092 & .048 & 1.002 & 1.201 & 1.439 \\
\hline Intentions & -.068 & .045 & .137 & .855 & .935 & 1.022 \\
\hline Sex & -2.014 & .636 & .002 & .038 & .133 & .464 \\
\hline \multicolumn{7}{|l|}{$\begin{array}{l}\text { Sometimes dieter vs. } \\
\text { Frequent dieter }\end{array}$} \\
\hline Intercept & 3.960 & 1.639 & .016 & & & \\
\hline Attitudes & .027 & .037 & .467 & .956 & 1.027 & 1.104 \\
\hline Norms & -.015 & .030 & .607 & .929 & .985 & 1.044 \\
\hline Perceived Behavioural Control & -.034 & .072 & .631 & .840 & .966 & 1.112 \\
\hline Intentions & -.076 & .039 & .053 & .857 & .926 & 1.001 \\
\hline Sex & -1.018 & & .087 & .113 & .361 & 1.159 \\
\hline
\end{tabular}

$\mathrm{R}^{2}=.152$ (Cox \& Snell), .177 (Nagelkerke). Model $\chi 2(10)=29.51, \mathrm{p}=.001$

Reference category for sex $=$ male 
Table 5: Multinomial logistic regression with TPB constructs and sex predicting dieting status.

\begin{tabular}{|c|c|c|c|c|c|c|}
\hline & \multirow[b]{2}{*}{$\boldsymbol{B}$} & \multirow[b]{2}{*}{ (SE) } & \multirow[b]{2}{*}{$\mathbf{p}$} & \multicolumn{3}{|c|}{ 95\% CI for Odds Ratio } \\
\hline & & & & Lower & $\begin{array}{l}\text { Odds } \\
\text { Ratio } \\
\end{array}$ & Upper \\
\hline Non dieter vs. Frequent dieter & & & & & & \\
\hline Intercept & 13.949 & 4.564 & .002 & & & \\
\hline Attitudes & -.083 & .053 & .115 & .829 & .920 & 1.020 \\
\hline Norms & .017 & .043 & .693 & .935 & 1.017 & 1.106 \\
\hline Perceived Behavioural Control & .055 & .114 & .629 & .845 & 1.057 & 1.320 \\
\hline $\begin{array}{l}\text { Favourability towards slim } \\
\text { prototype }\end{array}$ & -.085 & .050 & .088 & .833 & .918 & 1.013 \\
\hline $\begin{array}{l}\text { Favourability towards overweight } \\
\text { prototype }\end{array}$ & -.036 & .047 & .446 & .879 & .965 & 1.058 \\
\hline Similarity to slim prototype & .741 & .247 & .003 & 1.291 & 2.097 & 3.406 \\
\hline Similarity to overweight prototype & -.482 & .220 & .029 & .401 & .618 & .951 \\
\hline Intentions & -.098 & .056 & .080 & .813 & .907 & 1.012 \\
\hline Willingness to eat in social situation & -.047 & .044 & .285 & .876 & .954 & 1.040 \\
\hline Willingness to eat alone & -.144 & .080 & .072 & .741 & .866 & 1.013 \\
\hline Sex & -1.109 & .725 & .126 & .080 & .330 & 1.366 \\
\hline \multicolumn{7}{|l|}{$\begin{array}{l}\text { Sometimes dieter vs. Frequent } \\
\text { dieter }\end{array}$} \\
\hline Intercept & 7.577 & 3.267 & .020 & & & \\
\hline Attitudes & -.022 & .044 & .613 & .896 & .978 & 1.067 \\
\hline Norms & .016 & .032 & .613 & .954 & 1.017 & 1.083 \\
\hline Perceived Behavioural Control & -.101 & .085 & .239 & .765 & .904 & 1.069 \\
\hline $\begin{array}{l}\text { Favourability towards slim } \\
\text { prototype }\end{array}$ & -.044 & .035 & .204 & .894 & .957 & 1.024 \\
\hline $\begin{array}{l}\text { Favourability towards overweight } \\
\text { prototype }\end{array}$ & .038 & .031 & .221 & .977 & 1.039 & 1.105 \\
\hline Similarity to slim prototype & .287 & .172 & .094 & .952 & 1.333 & 1.867 \\
\hline Similarity to overweight prototype & -.311 & .170 & .067 & .525 & .732 & 1.022 \\
\hline Intentions & -.087 & .044 & .049 & .840 & .916 & 1.000 \\
\hline Willingness social & -.013 & .036 & .726 & .919 & .987 & 1.060 \\
\hline Willingness alone & -.022 & .061 & .720 & .869 & .979 & 1.102 \\
\hline Sex & -.551 & .646 & .394 & .162 & .577 & 2.046 \\
\hline
\end{tabular}

$\mathrm{R}^{2}=.301$ (Cox \& Snell), .351 (Nagelkerke). Model $\chi 2(22)=60.89, \mathrm{p}<.001$.

Reference category for sex $=$ male 


\section{Appendix A}

\section{Survey measures}

Note - titles in square brackets were not presented as headings to participants.

\section{[Attitudes to healthy eating:]}

Guidelines from the NHS say that a healthy diet includes eating at least five portions of fruit and vegetables a day, choosing high fibre or wholegrain options and limiting the amount of sugary high fat foods we eat. Please read and complete the following about healthy eating:

Eating healthy food is something which is

$\begin{array}{lll}\text { Pleasurable } & 1234567 & \text { Unpleasant } \\ \text { Confusing } & 1234567 & \text { Straightforward } \\ \text { Pointless } & 1234567 & \text { Important } \\ \text { Easy } & 1234567 & \text { Difficult }\end{array}$

When thinking about the foods that you choose to eat how much do you think about maintaining or reaching a healthy weight? Please read the following statement and indicate how you feel about it from 1-7 on the following scale:

Keeping my weight within a healthy range is

$\begin{array}{lll}\text { Desirable } & 1234567 & \text { Undesirable } \\ \text { Unimportant } & 1234567 & \text { Important } \\ \text { Enjoyable } & 1234567 & \text { Boring } \\ \text { Good for me } & 1234567 & \text { Bad for me }\end{array}$

\section{[Subjective and Descriptive Norms:]}

These questions are about how you think your friends and family would want you to behave:

Most people who are important to me think that I should eat a healthy diet with five portions of fruit and vegetable every day in the next two weeks.

Strongly disagree $\quad 1234567$ Strongly agree

It is expected of me that I limit the amount of sugary foods I eat every day in the next two weeks. Strongly disagree $\quad 1234567$ Strongly agree

I feel under social pressure to avoid eating fatty foods in the next two weeks.

Strongly disagree $\quad 1234567$ Strongly agree

These questions are about how you think your friends and family would behave:

Most people who are important to me would eat five portions of fruit and vegetables a day in the next two weeks.

Strongly disagree $\quad 1234567$ Strongly agree 
The people in my life whose opinion I value would approve of eating fatty foods in the next two weeks.

Strongly disagree $\quad 1234567$ Strongly agree

People who mean something to me would eat lots of sugary foods every day in the next two weeks.

Strongly disagree $\quad 1234567$ Strongly agree

Most people who are important to me would maintain or work towards having a slim and toned body.

Strongly disagree 1234567 Strongly agree

\section{[Measures of Intention:]}

I expect to eat five portions of fruit and vegetables a day in the next two weeks.

Strongly disagree $\quad 1234567$ Strongly agree

I plan not to eat high fat foods in the next two weeks.

Strongly disagree $\quad 1234567$ Strongly agree

I intend to eat sugary foods in the next two weeks.

Strongly disagree $\quad 1234567$ Strongly agree

I expect to maintain or work towards having a healthy weight in the next two weeks.

Strongly disagree $\quad 1234567$ Strongly agree

\section{[Measures of perceived behavioural control (PBC):]}

I am confident I could eat a healthy diet.

Strongly disagree $\quad 1234567$ Strongly agree

The decision to have a healthy weight is in my control.

Strongly disagree $\quad 1234567$ Strongly agree

Whether I have a slim and toned body or not is entirely up to me.

Strongly disagree $\quad 1234567$ Strongly agree

For me, eating a healthy diet with plenty of vegetables, fruit, high-fibre and low fat options is easy.

Strongly disagree $\quad 1234567$ Strongly agree

\section{[Assessment of prototypes:]}

\section{[Favourability]}

Some of the questions below concern your images of particular people. What we are interested in here are your ideas about typical members of a particular group. For example we all have ideas about what typical movie stars are like or what the typical grandmother is like. When asked if we could describe one of these images, we might say that we think the typical movie star is pretty or rich, or that the typical grandmother is sweet and frail. We are not saying that all movie stars or all grandmothers are exactly alike, but rather that many of them share certain characteristics. 
There will follow some brief descriptions of different types of people. Please read them and answer the questions.

Thinking about the typical person your age who is overweight, consider the following pairs of words and indicate where on the scale you feel the typical person your age who is overweight would be.

$\begin{array}{lrl}\text { Irresponsible } & 1234567 & \text { Responsible } \\ \text { Unreliable } & 1234567 & \text { Reliable } \\ \text { Selfish } & 1234567 & \text { Unselfish } \\ \text { Self-confident } & 1234567 & \text { Insecure } \\ \text { Unassertive } & 1234567 & \text { Assertive } \\ \text { Physically unattractive } 1234567 & \text { Physically attractive } \\ \text { Lazy } & 1234567 & \text { Hard working } \\ \text { Easy going } & 1234567 & \text { Uptight } \\ \text { Physically fit } & 1234567 & \text { Physically unfit } \\ \text { Stupid } & 1234567 & \text { Intelligent } \\ \text { Good company } & 1234567 & \text { Dull } \\ \text { Careless } & 1234567 & \text { Careful }\end{array}$

\section{[Prototype similarity:]}

How similar do you think you are to the typical person your age who is overweight?

Not at all similar $\quad 1234567$ Very similar

\section{[Favourability]}

Thinking about the typical person your age who is slim, consider the following pairs of words and indicate where on the scale you feel the typical person your age who is slim would be.

$\begin{array}{lrl}\text { Irresponsible } & 1234567 & \text { Responsible } \\ \text { Unreliable } & 1234567 & \text { Reliable } \\ \text { Selfish } & 1234567 & \text { Unselfish } \\ \text { Self-confident } & 1234567 & \text { Insecure } \\ \text { Unassertive } & 1234567 & \text { Assertive } \\ \text { Physically unattractive } 1234567 & \text { Physically attractive } \\ \text { Lazy } & 1234567 & \text { Hard working } \\ \text { Easy going } & 1234567 & \text { Uptight } \\ \text { Physically fit } & 1234567 & \text { Physically unfit } \\ \text { Stupid } & 1234567 & \text { Intelligent } \\ \text { Good company } & 1234567 & \text { Dull } \\ \text { Careless } & 1234567 & \text { Careful }\end{array}$

\section{[Prototype similarity:]}

How similar do you think you are to the typical person your age who is slim? Not at all similar $\quad 1234567$ Very similar

\section{[Measures of Willingness:]}

\section{[Willingness to eat in social situations]}


Suppose you are invited out for a meal with a group of friends to celebrate a birthday in the next two weeks. At the restaurant your friends are deciding what to eat and talking about the great chips at the restaurant and the delicious puddings. How willing would you be to order the chips and the pudding?

Not at all willing $\quad 1234567 \quad$ Very willing

Imagine you are invited to a friend's house for dinner in the next two weeks. You know that your friend serves big portions. How willing would you be to:

(a) Ask for a smaller portion

Not at all willing $\quad 1234567 \quad$ Very willing

(b) Leave some on the plate

Not at all willing $\quad 1234567$ Very willing

Suppose you are meeting up with a friend for tea/coffee in the next two weeks. Your friend suggests a café with great cakes. When you get there (s)he asks, "Shall we share or get one each?". How willing would you be to:

(a) Agree to two cakes

Not at all willing $\quad 1234567 \quad$ Very willing

(b) Agree to share a cake

Not at all willing $\quad 1234567 \quad$ Very willing

Suppose you are at a family or friend's celebration. There is a buffet with lots of delicious foods to choose from. There are different salads, cheeses, pastries, fruits and cakes. How willing would you be to:

(a) Only choose the healthier options

Not at all willing $\quad 1234567$ Very willing

(b) Choose mostly healthy options, but also a few unhealthy treats

Not at all willing $\quad 1234567 \quad$ Very willing

(c) Choose mostly the unhealthy options, because that is what you want and go back for more when you want to

Not at all willing $\quad 1234567$ Very willing

\section{[Willingness to eat alone]}

Imagine, in the next two weeks, you are at home after a long and stressful day at work or with your children. You have felt overwhelmed recently with things you need to do. How willing would you be to overeat any fatty or sugary foods that are in the house?

Not at all willing $\quad 1234567 \quad$ Very willing

Suppose, in the next couple of weeks, you have just got back home from a meal out with old friends who you haven't seen for a while. At the restaurant you chose healthy options and didn't 
have a pudding, although some of your friends had one. Now you are back home alone, how willing would you be to overeat any crisps of sugary foods that are in the house?

Not at all willing $\quad 1234567 \quad$ Very willing

Imagine, in the next two weeks, you are at home after a big argument with someone who is important to you (this could be a friend or close family member). How willing would you be to overeat any unhealthy foods that are in the house?

Not at all willing $\quad 1234567 \quad$ Very willing

\section{[Dieting behaviour:]}

Following is a list of possible descriptions about the practice of dieting in order to lose weight. Consider dieting to mean any change in your eating habits performed with the specific intention of losing weight. Your task is to indicate which statement best describes you by placing an $\mathrm{X}$ next to the most appropriate statement. Place an X next to one statement only.

1. I have NEVER dieted in order to lose weight.

2. I am probably best described as a TRIER, because I have given it a go but never really got very far.

3. I would regard myself an EX-DIETER. I used to regularly go on a diet to lose weight, but no longer do so.

4. I SOMETIMES diet in order to lose weight, but not on a regular basis.

5. I OFTEN diet in order to lose weight.

6. I am ALWAYS dieting in order to lose weight.

\section{[Demographics:]}

Age: $25-34 ; 35-44 ; 45-54 ; 55-64 ; 65-74 ; 75-84$

Marital status: Married; Divorced; Living with partner; Single; widowed

How many people usually live in your household? Adults / Children (under 18)

What is your highest level of educational attainment?

Btech/GCSE's/O levels; A levels; Degree; Post Graduate study.

Occupation (tick all that apply / if more than one apply tick the one that takes up the majority of your time): Student / Employed / Part time work / Full time work / Full time carer

Height: (in Feet/ metres)

Weight: (in stones / kg)

Male / Female / Prefer not to say 